\title{
Sealing properties and structure optimization of packer rubber under high pressure and high temperature
}

\author{
Wen-Jian Lan ${ }^{1} \cdot$ Han-Xiang Wang ${ }^{1} \cdot$ Xin Zhang $^{1} \cdot$ Sheng-Shan Chen ${ }^{1}$
}

Received: 27 April 2018 / Published online: 2 January 2019

(c) The Author(s) 2018

\begin{abstract}
During hydraulic fracturing operations of low-permeability reservoirs, packers are the key component to ensure the success of multistage fracturing. Packers enable sections of the wellbore to be sealed off and separately fractured by hydraulic pressure, one at a time, while the remainder of the wellbore is not affected. However, reliable sealing properties of the packer rubber are required to meet the high-pressure and high-temperature (HPHT) conditions of reservoirs (such as $70 \mathrm{MPa}$ and $170{ }^{\circ} \mathrm{C}$ ). In this study, the structures of the packer rubber with two different materials are optimized numerically by ABAQUS and validated by experiments. The optimization process starts from the packer rubber with a conventional structure, and then, the weakest spots are identified by ABAQUS and improved by slightly varying its structure. This process is iterative, and the final optimized structure of a single rubber barrel with expanding back-up rings is achieved. For the structure of three rubber barrels with metallic protective covers, both HNBR and AFLAS fail under HPHT conditions. For the final optimized structure, the packer rubber made of AFLAS can work better under HPHT than that made of HNBR which ruptures after setting. The results show that the optimized structure of a single rubber barrel with expanding back-up rings and the material AFLAS are a good combination for the packer rubber playing an excellent sealing performance in multistage fracturing in horizontal wells.
\end{abstract}

Keywords Packer rubber · Sealing property $\cdot$ Structure optimization · Hydrogenated nitrile-butadiene rubber (HNBR) AFLAS rubber

\section{Introduction}

At present, many oil fields in China have come into the middle and late stages of production. In order to guarantee the stability of the oil and gas production, unconventional oil and gas reservoirs and low-permeability reservoirs are the major goals of exploration and development (Wang et al. 2015; Liu et al. 2016; Zeng et al. 2016). However, because of their low permeability and poor production, it is necessary to fracture the oil and gas wells. Staged fracturing completion technology in horizontal wells is an advanced and effective measure of enhancing oil and gas production and recovery ratios during the exploration of low-permeability

Edited by Yan-Hua Sun

Han-Xiang Wang

wanghx_upc@163.com

1 College of Mechanical and Electronic Engineering, China University of Petroleum, Qingdao 266580, Shandong, China reservoirs (Economides and Nolte 2000; Love et al. 2001; Ye et al. 2008), and packers are key equipment to complete multistage fracturing successfully. However, high demands on the materials and the structure of the packer rubber are required to meet the high-pressure and high-temperature (HPHT) conditions of reservoirs.

Recently, efforts have been taken to study the sealing properties of packer rubber through theoretical calculation, numerical simulation and experimental methods. The materials and the structure are the important factors that affect the sealing properties of the packer rubber. Zhu et al. (2017) made comparisons on the mechanical performances and morphology of three kinds of rubber materials (NBR, HNBR and FKM) before and after corrosion experiments, and the results showed that the tensile properties decreased significantly and the hardness also reduced after corrosion. He et al. (2016) investigated hydrogenated nitrile-butadiene rubber (HNBR) with a Rubber Processing Analyzer RPA2000 and conducted stress-strain tests in both elongation and compression modes. In order to reflect the applications 
of packers, all the mechanical properties were tested at both room temperature (RT) and $150{ }^{\circ} \mathrm{C}$. Zeng et al. (2012) carried out tests on AFLAS rubber (a copolymer of tetrafluoroethylene and propylene) using a HPHT autoclave in harsh environments $\left(60 \mathrm{MPa}, 175^{\circ} \mathrm{C}\right.$, test period 7 days and different corrosive gases) and analyzed the changes in properties. Atkinson et al. (2001) and Guo et al. (2011) analyzed the touch stress and pressure in the inner wall of the rubber part with nonlinear finite element analysis and optimized the rubber wall thickness through some advantaged plans to bear much stronger stress. Ma et al. (2014) and Qu (2016) constructed a finite element simulation model of double elastomeric packing elements in a packer using ANSYS software and analyzed the influences of different friction coefficients, the loading model and the different angles of the tilted end of the packing element on the varying patterns of contact stress between the packing element and the casing pipe. Polonsky and Tyurin (2015) came up with a new structure design for packers after discussing several designs aiming at enhancing sealing reliability and considering the packers' working conditions. In order to solve the technical problems of deep wells and complex formations, James et al. (2013) improved the temperature resistance and the pressure resistance of the permanent production packer from $69 \mathrm{MPa}$ and $121{ }^{\circ} \mathrm{C}$ to $138 \mathrm{MPa}$ and $132{ }^{\circ} \mathrm{C}$ after many years of studies. Zhang et al. (2011) and Wang et al. (2014) experimentally investigated the working force between the packer rubber and the casing tube and the stress-strain curves of packer rubber material at different temperatures, which provide the basis for establishing constitutive relations of packer rubbers.

At present, most scholars have investigated the material properties of packer rubber by the use of dumbbellshaped specimens and simple cylindrical specimens, and their conclusions indicated that many rubber materials such as HNBR and AFLAS have better pressure resistance and high-temperature resistance. However, the influence of the actual structures and shapes on sealing performance of packer rubber is seriously considered. The packer rubber made of high-performance material may have poor sealing performance under conditions of high pressure and high temperature in low-permeability reservoirs because of an unreasonable structure. In this paper, the study begins with packer rubber with a conventional structure and optimizes the materials and the structure of the packer rubber by ABAQUS software simulation and experimental research. In the experiments, rubber sleeves are installed on a packer and a function test scheme of the packer is designed which can simulate the packer setting and its working conditions.

\section{Theory basis}

\subsection{Selection of the rubber materials}

The selection of rubber materials is a key factor in the packer design, because the maximum operating differential pressure and the maximum operating temperature of the packer are primarily limited by the material of the rubber barrel. The main rubber materials of the compression packer are fluorine rubber, nitrile rubber, hydrogenated nitrile rubber and AFLAS rubber (a new fluorine rubber based on tetrafluoroethylene and propylene copolymer), the advantages and disadvantages of these rubber materials are given in Table 1, and hydrogenated nitrile-butadiene rubber (HNBR) and AFLAS fluoro rubber are considered in the following sections (Choudhury et al. 2010a, b; Alcock and Jørgensen 2015).

Because of the high nonlinearity and superelasticity of rubber material (great deformation is obtained under a very little force), it is difficult to obtain a reasonable structure of the sealing unit by a theoretical calculation when designing packer rubber. In the analysis and calculation of rubber components, there are many constitutive models to describe the relationship between the stress tensor and strain tensor of the rubber materials, such as Mooney-Rivlin model, Yeoh model and Gent model. Different rubber constitutive models

Table 1 Comparison of the rubber material performance

\begin{tabular}{|c|c|c|}
\hline Rubber material & Advantages & Disadvantages \\
\hline Fluorine rubber & Good heat resistance and aging resistance & $\begin{array}{l}\text { Poor plasticity, difficult to machine and form, strength and } \\
\text { hardness decreasing with increasing temperature, high } \\
\text { cost }\end{array}$ \\
\hline Nitrile rubber & $\begin{array}{l}\text { Good heat resistance and oil resistance, high tensile } \\
\text { strength and elasticity, easy forming, low cost }\end{array}$ & $\begin{array}{l}\text { Easy to lose efficacy under high temperatures and high } \\
\text { pressures (when } T>150{ }^{\circ} \mathrm{C}, P>35 \mathrm{MPa} \text { ) }\end{array}$ \\
\hline $\begin{array}{l}\text { Hydrogenated nitrile- } \\
\text { butadiene rubber } \\
\text { (HNBR) }\end{array}$ & $\begin{array}{l}\text { Good heat resistance and oil resistance, higher wear } \\
\text { resistance and pressure resistance than nitrile rubber }\end{array}$ & $\begin{array}{l}\text { Great intermolecular forces, high viscosity, slightly poor } \\
\text { processability }\end{array}$ \\
\hline AFLAS rubber & $\begin{array}{l}\text { Excellent heat resistance, oil resistance and acid-base } \\
\text { resistance property, long service life and high-tempera- } \\
\text { ture limit in thermal and corrosive environments }\end{array}$ & High cost, poor low-temperature resistance \\
\hline
\end{tabular}


are suitable for different rubber materials. The Yeoh model can use the uniaxial tensile test to simulate the mechanical behavior of rubber materials under a large deformation, but it is not suitable for moderate and small deformations. The Gent model can simulate the strain energy of the rubber materials under a large deformation which is mainly applied to thin-walled spheres, hollow rubber and thin-walled cylindrical tubular bodies subjected to an internal pressure, but it is also not suitable for small and moderate deformations. The Mooney-Rivlin model can fit the relationship between the stress and strain of the incompressible rubber materials in moderate deformation. Therefore, the Mooney-Rivlin constitutive model is selected in this study.

The strain energy density function in the Mooney-Rivlin model is expressed as:

$W=C_{10}\left(I_{1}-3\right)+C_{01}\left(I_{2}-3\right)$

where $W$ is the strain potential energy, $I_{1}$ and $I_{2}$ are the deformation tensors and $C_{10}$ and $C_{01}$ are the Mooney material coefficients.

For an incompressible rubber material, its Poisson's ratio can be set as 0.5. The relationship among the elastic modulus $E_{0}$, the shear modulus $G_{0}$ and the material coefficients of the rubber material at a small strain can be expressed as follows:

$G_{0}=\frac{E_{0}}{3}=2\left(C_{10}+C_{01}\right)$

According to the experimental data fitting of rubber hardness $H$ and elastic modulus $E_{0}$, the relationship between them can be obtained:

$\lg E_{0}=0.0198 H-0.5432$

With Eqs. (2) and (3), the relationship between hardness $H$ and material coefficients $\left(C_{10}\right.$ and $\left.C_{01}\right)$ can be expressed as follows:

$6 C_{10}\left(1+\frac{C_{01}}{C_{10}}\right)=10^{0.0198 H-0.5432}$

According to the relevant literature about the tensile test of rubber materials, the ratio of $C_{10}$ to $C_{01}$ roughly ranges from 0.3 to 0.7 . 0.5 is selected in this study. Therefore, if the hardness of the rubber material is known, the values of the material coefficients $C_{10}$ and $C_{01}$ can be determined by Eq. (4). The mechanical properties of the constitutive model for rubber material are given in Table 2.

\subsection{Calculation of the packer setting force}

The calculation model of the packer setting force is shown in Fig. 1. In the packer setting, a compressive force (that is packer setting force) acts on the head face of the annulus packer rubber and compresses the packer rubber, which leads to the packer rubber expanding radially and contacting with the inner
Table 2 Mechanical properties of the constitutive model for rubber material

\begin{tabular}{lllll}
\hline $\begin{array}{l}\text { Order } \\
\text { number }\end{array}$ & $\begin{array}{l}\text { Hardness } H, \\
\text { IRHD }\end{array}$ & $\begin{array}{l}\text { Elastic modulus } \\
E_{0}, \mathrm{MPa}\end{array}$ & \multicolumn{2}{l}{$\begin{array}{l}\text { Material coeffi- } \\
\text { cients of rubber }\end{array}$} \\
\cline { 3 - 5 } & & & $C_{10}$ & $C_{01}$ \\
\hline 1 & 60 & 4.42 & 0.491 & 0.294 \\
2 & 65 & 5.54 & 0.616 & 0.307 \\
3 & 70 & 6.96 & 0.774 & 0.387 \\
4 & 75 & 8.75 & 0.972 & 0.486 \\
5 & 80 & 10.98 & 1.221 & 0.610 \\
6 & 85 & 13.80 & 1.533 & 0.767 \\
7 & 90 & 17.33 & 1.926 & 0.963 \\
8 & 95 & 21.77 & 2.420 & 1.410 \\
\hline
\end{tabular}

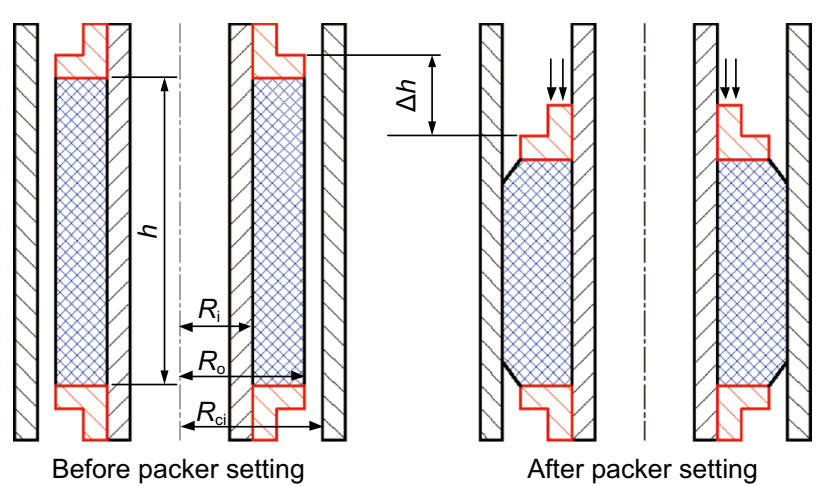

Fig. 1 Force analysis diagram of the packer rubber before and after setting

wall of the casing. In order to achieve a good sealing effect, the setting force should further compress the packer rubber to make sure that the friction force between the packer rubber and the casing due to the contact pressure is greater than the operating differential pressure. The packer setting force includes two parts: the compressive force required to make the sealing element contact with the inner wall of the casing and the compressive force to make the sealing element expand from contacting with the inner wall of the casing to meet the required sealing effect (Gent 2012; Zhu 2012).

In the calculation, Poisson's ratio for the sealing element is about 0.5 , so that the element can be considered incompressible. When the inner diameter of the casing $R_{\mathrm{ci}}$ is $76.2 \mathrm{~mm}$, the axial relative elongation is obtained:

$\varepsilon_{z}=\frac{2 R_{\mathrm{ci}}\left(R_{\mathrm{ci}}-R_{\mathrm{o}}\right)}{\left(R_{\mathrm{ci}}^{2}-R_{\mathrm{i}}^{2}\right)}=0.16458$

Taking into account the shape of the packer rubber, if the overall length of the packer rubber is $250 \mathrm{~mm}$, its compression distance is: 
$\Delta h=h \varepsilon_{z}=41.145 \mathrm{~mm}$

According to the generalized Hooke law, the compressive force $F_{\varepsilon}$ required to make the sealing element contact with the inner wall of the casing is:

$F_{\varepsilon}=2 \pi \frac{E R_{\mathrm{ci}}}{1+\mu}\left(R_{\mathrm{ci}}-R_{\mathrm{o}}\right)=9.307 \mathrm{kN}$

The compressive force $F_{\Delta P}$ required to make the sealing element expand from contacting with the inner wall of the casing to meet the required sealing effect is:

$F_{\Delta P}=\frac{\pi \Delta P\left(R_{\mathrm{ci}}^{2}-R_{\mathrm{i}}^{2}\right)\left(R_{\mathrm{o}}^{2}-R_{\mathrm{i}}^{2}\right)}{4 f R_{\mathrm{i}} h\left(1-\varepsilon_{z}\right)}=79.968 \mathrm{kN}$

Therefore, the packer setting force $F$ required to ensure the sealing of the sealing element is:

$F=F_{\varepsilon}+F_{\Delta P}=89.275 \mathrm{kN}$

Finally, according to the packer setting force, the setting pressure in the piston chamber can be obtained:

$P=\frac{F}{\pi\left(R_{2}^{2}-R_{3}^{2}\right)}=22.734 \mathrm{MPa}$

According to the structure size of the packer, the ratio of the compression ring area to the piston area is 1.75 . Therefore, the setting pressure which acts on the packer rubber is:

$P_{0}=\frac{P}{1.75}=13 \mathrm{MPa}$

where $F$ is the total compressive force; $F_{\varepsilon}$ is the compressive force required to make the sealing element contact with the inner wall of the casing; $F_{\Delta P}$ is the compressive force required to achieve the sealing under the effect of differential pressure; $\Delta P$ is the differential pressure acting on the packer, $70 \mathrm{MPa} ; f$ is the friction coefficient, $0.3 ; E$ is the elastic modulus, $10.8 \mathrm{MPa} ; R_{\mathrm{ci}}$ is the inner diameter of the casing, $76.2 \mathrm{~mm} ; R_{\mathrm{i}}$ is the inner diameter of the packer rubber, $57.5 \mathrm{~mm} ; R_{\mathrm{o}}$ is the outer diameter of the packer rubber, $73.5 \mathrm{~mm} ; h$ is $250 \mathrm{~mm} ; \varepsilon_{z}$ is the axial relative deformation; $\mu$ is Poisson's ratio, $0.5 ; R_{2}$ is the outer diameter of the piston, $67.5 \mathrm{~mm} ; R_{3}$ is the inner diameter of the piston, $57.5 \mathrm{~mm}$.

When the casing sizes are 76.20, 77.40, 78.55 and $79.85 \mathrm{~mm}$, the calculation processes are the same as the above calculation process, and the results are summarized in Table 3.

\subsection{Calculation of the average contact pressure}

After packer setting, there will be a certain differential pressure on both ends of the packer rubber during the working process. Therefore, the average contact pressure $P_{\mathrm{c}}$ between the packer rubber and the casing includes two parts: the contact pressure $P_{\mathrm{cl}}$ due to the compressive force $F_{\Delta P}$ in the setting stage and the contact pressure $P_{\mathrm{c} 2}$ due to the differential pressure $\Delta P$ in the working stage.

$P_{\mathrm{c}}=P_{\mathrm{c} 1}+P_{\mathrm{c} 2}$

The contact pressure $P_{\mathrm{c} 1}$ can be obtained as follows:

$P_{\mathrm{c} 1}=\frac{\mu}{1-\mu} \frac{F_{\Delta P}}{\pi\left(R_{\mathrm{ci}}^{2}-R_{\mathrm{i}}^{2}\right)}$

The contact pressure $P_{\mathrm{c} 2}$ is:

$P_{\mathrm{c} 2}=\frac{\mu}{1-\mu} \Delta P$

According to Eqs. (12), (13) and (14), the average contact pressures of different casing sizes are given in Table 4.

\section{Sealing study and structure optimization}

\subsection{Conventional structure}

As the key component of the packer, the structure of the rubber directly influences the sealing properties of the packer. As shown in Fig. 2, the structure of the regular packer seal unit is a combination of three rubber barrels, which are separated by metal calking rings.

Table 4 Average contact pressures of different casing sizes

\begin{tabular}{lllll}
\hline$R_{\mathrm{ci}}, \mathrm{mm}$ & $\Delta P, \mathrm{MPa}$ & $\Delta h, \mathrm{~mm}$ & $P, \mathrm{MPa}$ & $P_{\mathrm{c}}, \mathrm{MPa}$ \\
\hline 76.20 & 70 & 41.15 & 22.73 & 2.4 \\
77.40 & 70 & 56.25 & 27.00 & 4.0 \\
78.55 & 70 & 69.25 & 31.50 & 5.7 \\
79.85 & 70 & 82.50 & 36.75 & 7.8 \\
\hline
\end{tabular}

Table 3 Setting pressures in the piston chamber for different casing sizes

\begin{tabular}{lllrrrr}
\hline$R_{\mathrm{ci}}, \mathrm{mm}$ & $\varepsilon_{z}$ & $\Delta h, \mathrm{~mm}$ & $F_{\varepsilon}, \mathrm{kN}$ & $F_{\Delta P}, \mathrm{kN}$ & $F, \mathrm{kN}$ & $P, \mathrm{MPa}$ \\
\hline 76.20 & 0.165 & 41.15 & 9.302 & 79.962 & 89.264 & 22.73 \\
77.40 & 0.225 & 56.25 & 13.649 & 92.511 & 106.164 & 27.00 \\
78.55 & 0.277 & 69.25 & 17.936 & 105.789 & 123.725 & 31.50 \\
79.85 & 0.330 & 82.50 & 22.927 & 122.374 & 144.253 & 36.75 \\
\hline
\end{tabular}




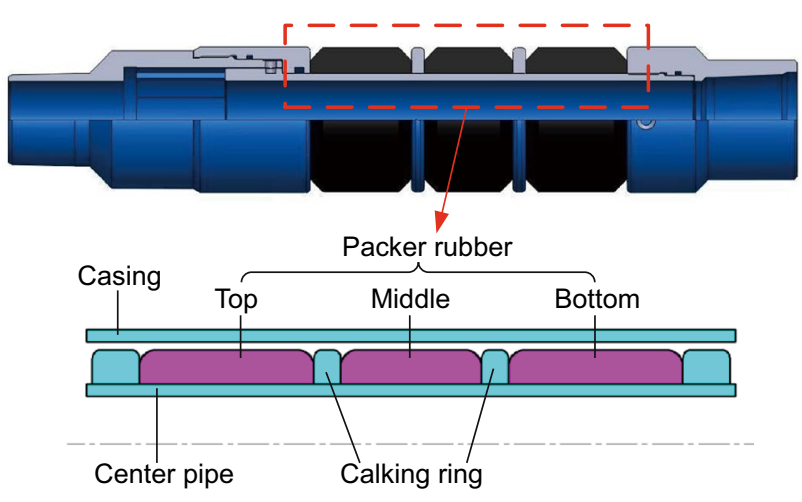

Fig. 2 Structure of three regular rubber barrels

In order to study the sealing properties and structure optimization of the packer rubber at high pressures and high temperatures, the process of the packer rubber setting is simulated using the finite element software ABAQUS to provide a theoretical basis for structure optimization before experiments. In the simulation, some assumptions are made as follows without affecting the function of the packer: (1) The packer is always located in the center of the casing and is symmetric around the centerline of the casing; (2) the effect of the packer's self-weight to simulation results is neglected; (3) only the packer rubber is analyzed, and the bottom calking ring, the center pipe and the casing are stationary in the simulation.

Component materials: The material of the center pipe is $35 \mathrm{CrMo}$; the materials of calking rings and casing are 45 steel. The elastic moduli of the calking rings, the center pipe and the casing are $2.1 \times 10^{5} \mathrm{MPa}$, and their Poisson's ratios are 0.3. The Mooney-Rivlin model is used in the simulation of the rubber. Because the cost of AFLAS is higher than that of HNBR and AFLAS is mainly imported in China, HNBR is chosen as the material of packer rubber at first. The hardness of the top and bottom rubber barrels is 90 IRHD, and that of the middle rubber barrel is 80 IRHD.

Modeling and meshing: The 2D axisymmetric model is chosen in modeling, because the packer is symmetric around the centerline of the casing. The mesh type of the packer rubber is the CAX4RH element, and the other parts use the default element. The friction coefficient between the packer rubber and metal parts is set as 0.3. The analysis model of three regular rubber barrels is established and meshed as shown in Fig. 3.

Boundary conditions: The bottom calking ring, the center pipe and the casing are stationary. A pressure of $13 \mathrm{MPa}$ is applied to the top calking ring to compress the packer rubber. The simulation results are shown in Fig. 4.

According to the analytical results shown in Figs. 4 and 5 , although the sealing element with three rubber barrels has a simple structure and the contact pressure on the top

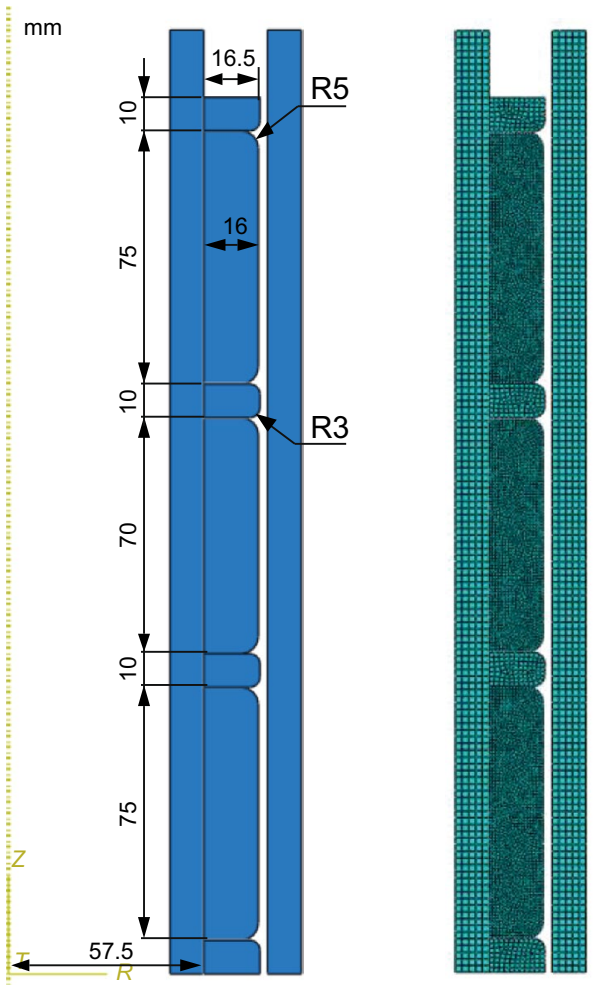

Fig. 3 Finite element model of three regular rubber barrels

rubber barrel end is larger (the average contact pressure is $5.01 \mathrm{MPa}>P_{\mathrm{c}}\left(P_{\mathrm{c}}=2.4 \mathrm{MPa}\right)$, which is given in Table 4), the middle and bottom rubber barrels are not fully compressed, which results in smaller contact pressure (their average contact pressures are 1.15 and $0.25 \mathrm{MPa}$, respectively). In the packer setting process, the shoulder protrusion happens to the top and middle rubber barrels. The results show that the conventional structure of three rubber barrels has poor sealing properties, which does not fit the conditions of high temperature and high pressure.

\subsection{Structure optimization plan 1: adding protective covers on both ends}

For preventing the shoulder protrusion, metallic protective covers made of red copper are added at both ends of the top and bottom rubber barrels. In order to increase the compression of the packer rubber and improve the contact pressure, the middle rubber barrel is also equipped with a sealing groove at the middle of its inner wall. The new structure of the packer rubber is shown in Fig. 6.

Modeling: As shown in Fig. 7, the modeling progress of the new structure of the packer rubber with metallic protective covers is the same as that of the conventional structure. The elastic modulus of metallic protective covers is $1.07 \times 10^{5} \mathrm{MPa}$, and its Poisson's ratio is 0.36 . The 
Mises, MPa

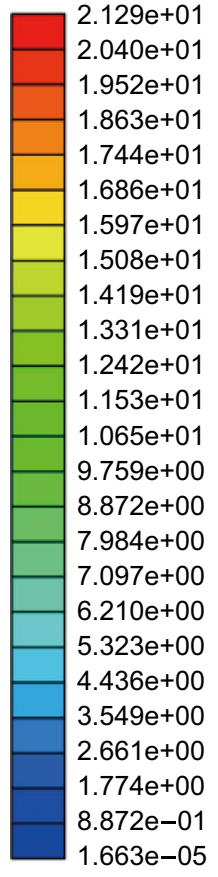

Magnitude, $\mathrm{mm}$

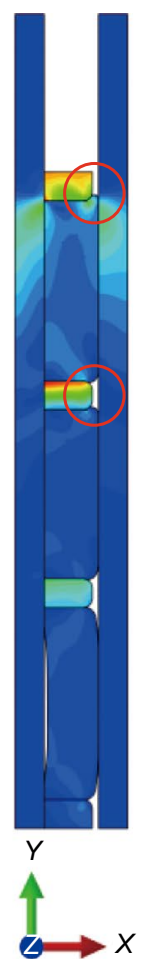

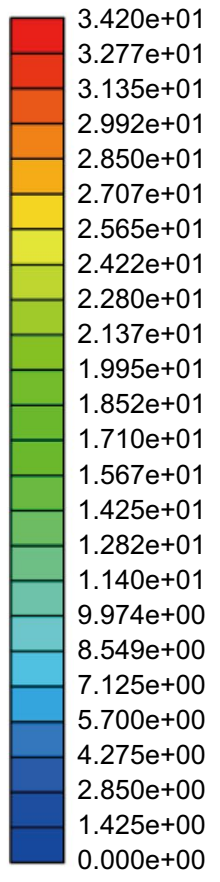

Fig. 4 Equivalent stress, strain and contact pressure distribution under $13 \mathrm{MPa}$

Contact pressure, $\mathrm{MPa}$

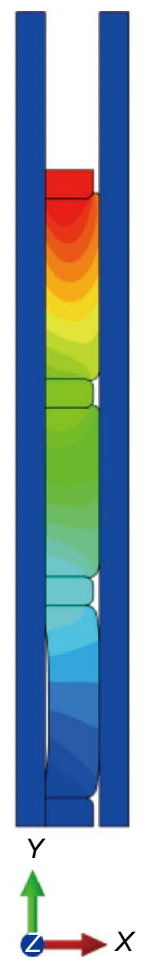

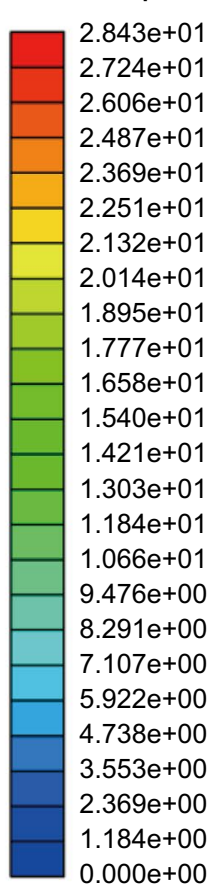

$43 e+01$

$2.606 \mathrm{e}+01$

$2.487 e+01$

$2.369 \mathrm{e}+01$

$2.251 \mathrm{e}+01$

$2.132 \mathrm{e}+01$

$.014 \mathrm{e}+01$

$1.777 e+01$

$1.658 \mathrm{e}+01$

$1.540 \mathrm{e}+01$

$1.421 \mathrm{e}+01$

$.303 e+01$

$1.184 \mathrm{e}+01$

$1.066 \mathrm{e}+01$

$9.476 \mathrm{e}+00$

$8.291 e+00$
$7.107 e+00$

$5.922 \mathrm{e}+00$

$4.738 \mathrm{e}+00$

$3.553 e+00$

$2.369 \mathrm{e}+00$

$0.000 \mathrm{e}+00$

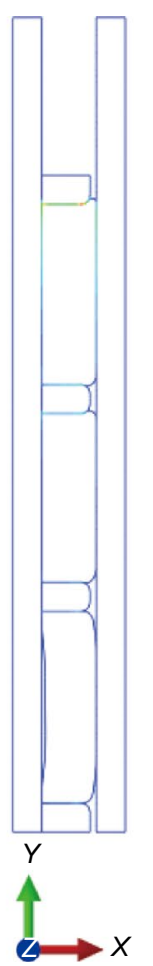

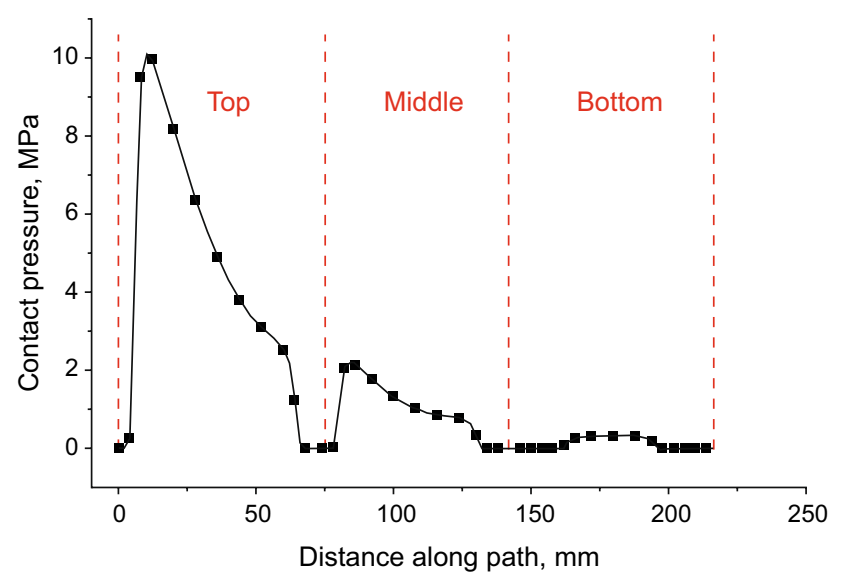

Fig. 5 Contact pressure distribution of three regular rubber barrels

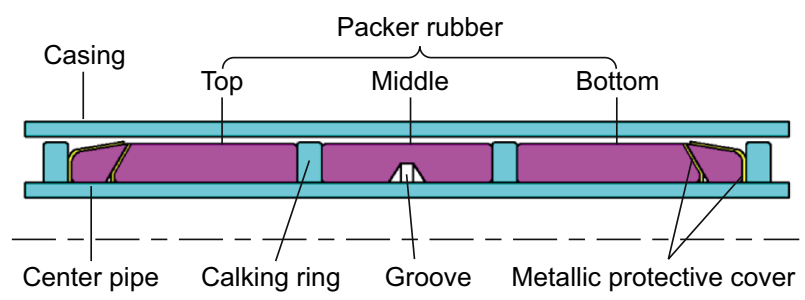

Fig. 6 Structure of three rubber barrels with metallic protective covers materials of other components are identical to those of the conventional structure. The mesh type of the packer rubber is the CAX4RH element, and the other parts use the default element. The friction coefficient among metallic protective covers, calking rings and the center pipe is 0.1 , and that between the packer rubber and the metal parts is set as 0.3 . The bottom calking ring, the center pipe and the casing are stationary. A pressure of $13 \mathrm{MPa}$ is applied to the top calking ring to compress the packer rubber.

The results simulated by ABAQUS are shown in Fig. 8.

According to the analytical results shown in Figs. 8 and 9, the addition of metallic protective covers prevents the shoulder protrusion of the packer rubber and extends its service life. Three rubber barrels are fully compressed because of the sealing groove. (Its compression distance is $40.98 \mathrm{~mm}$, which is larger than that of the conventional structure $34.2 \mathrm{~mm}$.) The contact pressures on the top, middle and bottom rubber barrels (the average values are 5.43, 1.40 and $0.46 \mathrm{MPa}$, respectively; the maximum values are 7.61, 3.40 and $0.56 \mathrm{MPa}$, respectively) are larger than those in the conventional structure of three rubber barrels. The results show that the new structure of three rubber barrels with metallic protective covers has better sealing properties than the conventional structure.

In order to examine the sealing properties of the new packer rubber under high temperature and high pressure, 


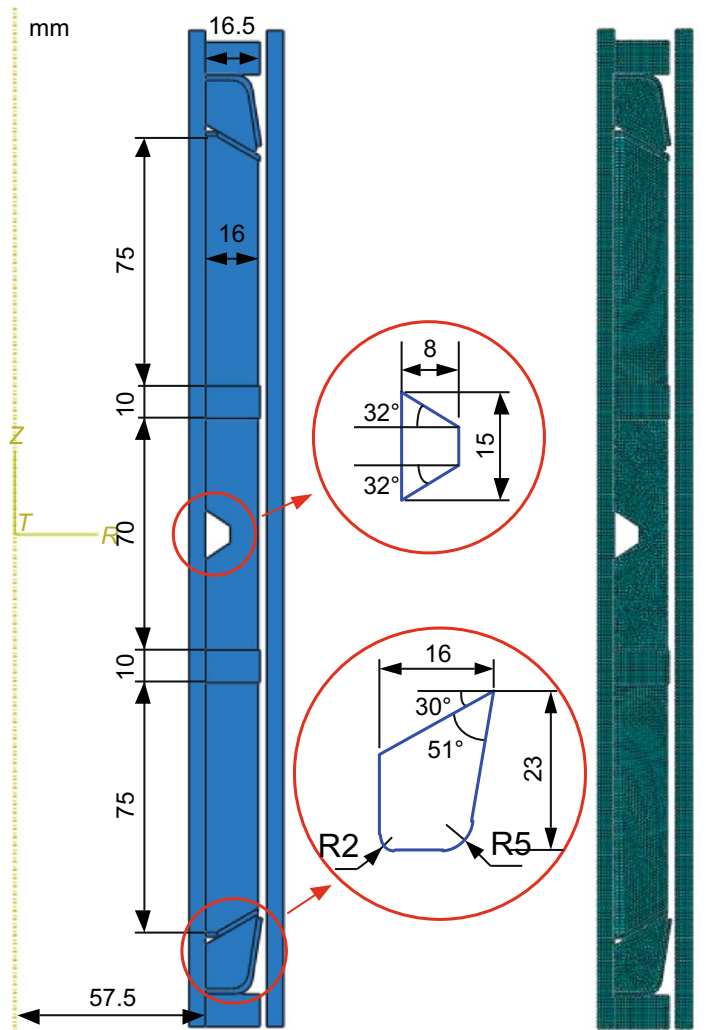

Fig. 7 Finite element model of the new structure with metallic protective covers

packer performance tests were done. The test scheme is shown in Fig. 10. Two groups of the rubber barrels made of HNBR were installed on a packer, which was placed in a 6-in $(152.4 \mathrm{~mm})$ casing, as shown in Figs. 11 and 12. The packer and the casing were dipped in an oil bath at $170{ }^{\circ} \mathrm{C}$. By use of a high-pressure pump, hydraulic oil was injected into the packer from Hole 1 to set the packer rubber. The other end of the packer was sealed by a plug, so was the casing (2-end). After packer setting, the sealing properties of the packer rubber were tested by pressurizing the annulus between the packer and the casing from Hole 3 and Hole 5. Then, the sealing pressures in Hole 3 and Hole 5 were recorded.

However, the maximum sealing pressure only reached $35 \mathrm{MPa}$ during the experiment. After the test, two groups of rubber barrels were removed, as shown in Fig. 13. The rubber barrels made of HNBR were seriously ruptured and the cracks are very apparent. The experimental results show that the packer rubber made of HNBR cannot meet the sealing requirement under high pressure $(70 \mathrm{MPa})$ and high temperature $\left(170^{\circ} \mathrm{C}\right)$.

With other conditions being equal, the material of the packer rubber was changed to AFLAS rubber which has excellent heat resistance, oil resistance and acid-base resistance. Two groups of rubber barrels made of AFLAS rubber were also installed on the packer, and the tests were done twice. However, the maximum sealing pressures of two tests only reached 50 and $53 \mathrm{MPa}$, respectively. The rubber barrels were removed after tests, as shown in Fig. 14. Although all the rubber barrels were not broken in the two tests, they were not fully compressed and the metallic protective covers at both ends of the top and bottom rubber barrels were torn, which led to a poor sealing performance. The results show that the AFLAS rubber can work at a high temperature $\left(170{ }^{\circ} \mathrm{C}\right)$; however, the composite construction of three rubber barrels which looks like tomatoes on sticks cannot meet the sealing requirements under high pressure and needs to be improved further.

\subsection{Structure optimization plan 2: Single rubber barrel with expanding back-up rings}

Although the composite construction of three rubber barrels with metallic protective covers can prevent the shoulder protrusion, the contact pressures of three rubber barrels are very different. Therefore, the new structure of a single rubber barrel with expanding back-up rings (shown in Fig. 15) is selected in place of the construction of three rubber barrels, because the middle rubber barrel plays a major sealing role.

In the new structure, the material of the single rubber barrel is still AFLAS rubber and there are two metal conical rings at both ends of the rubber barrel instead of the top and bottom rubber barrels in the construction of three rubber barrels to bear the thrust for setting. There are two sets of expanding back-up rings among the conical rings and the rubber barrel for preventing the shoulder protrusion. One set of expanding back-up rings is made of an outer ring and an inner ring. The two rings are embedded in each other to ensure good contacts, and there is a small gap on each ring which is convenient for expanding. A dovetail groove is cut in the inner wall of the rubber barrel. There are a bearing flow ring made of metal and a seal ring (O-ring) to seal the space between the rubber barrel and the center pipe. Through the experimental measurement, the setting force to compress the new packer rubber is 15 tonnes $(F=150$ $\mathrm{kN}$ ) when the new packer rubber is tested in a 7-inch casing. The pressure $P_{\mathrm{s}}$ applied to the top of the conical ring to set the packer is

$P_{\mathrm{s}}=\frac{F}{S_{\mathrm{c}}}=\frac{150000}{2180.23} \mathrm{~Pa}=68.8 \mathrm{MPa}$

where $S_{\mathrm{c}}$ is the end face area of the top conical ring.

First, the setting process of the new packer rubber is still simulated using ABAQUS before experiment. Modeling: As shown in Fig. 16, the modeling progress of the new structure of the packer rubber is the same as that of the 

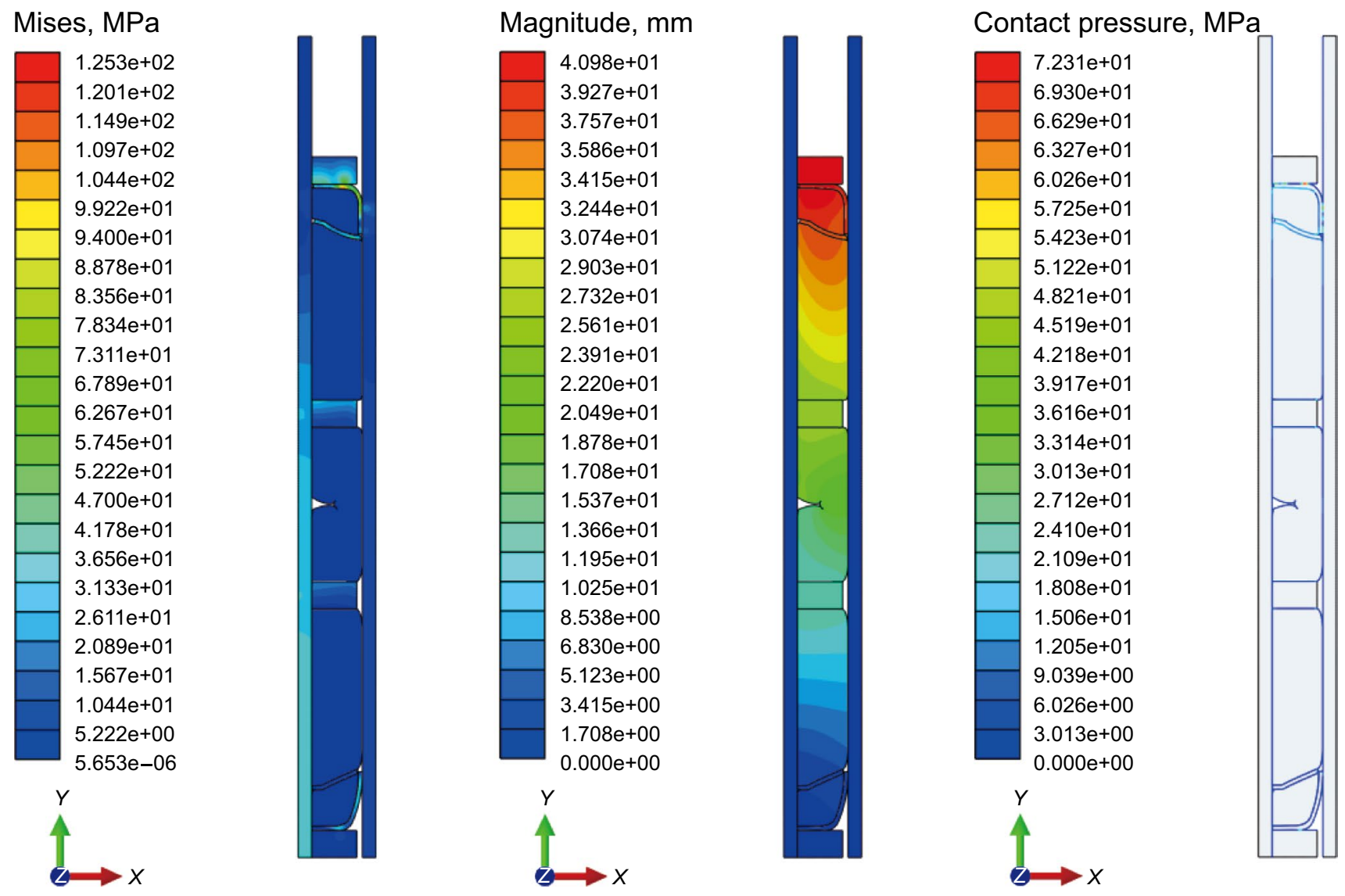

Fig. 8 Equivalent stress, strain and contact pressure distributions

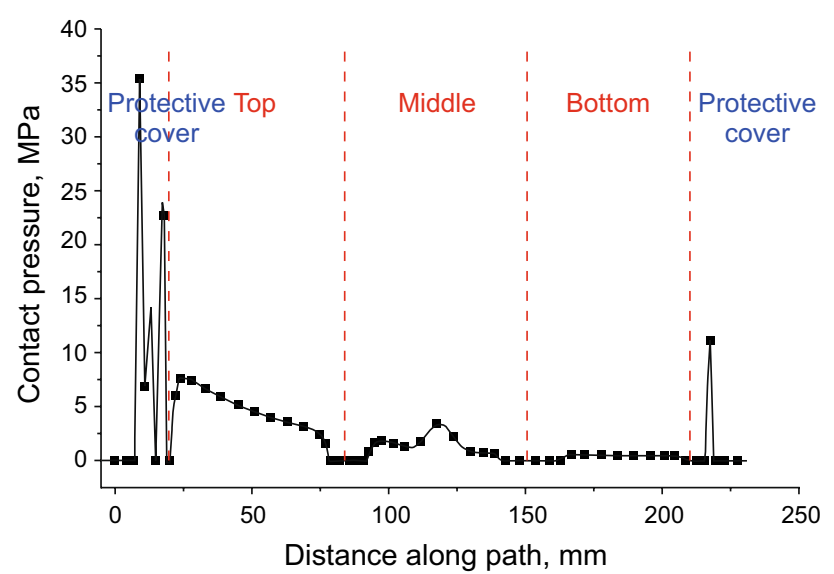

Fig. 9 Contact pressure distribution of the new structure with metallic protective covers

conventional structure. The hardness of the rubber barrel is 80 IRHD. The materials of the conical rings and the center pipe are $35 \mathrm{CrMo}$, whose elastic modulus is $2.16 \times 10^{5} \mathrm{MPa}$ and Poisson's ratio is 0.286 . The material of the casing is 45 steel, and the materials of back-up rings are 20 steel.
The elastic moduli of the casing and the back-up rings are $2.06 \times 10^{5} \mathrm{MPa}$, and their Poisson's ratios are 0.3 . The possible contact among each part before and after deformation is set. The friction coefficient among metal parts is 0.1 , and that between the packer rubber and the metal parts is set as 0.3 . The bottom conical ring, the center pipe and the casing are stationary. A pressure of $68.8 \mathrm{MPa}$ is applied to the end face of the top conical ring to compress the packer rubber. The results simulated by ABAQUS are shown in Fig. 17.

As shown in Fig. 18, the contact pressure between the casing and the packer rubber with expanding back-up rings (the average value is $9.75 \mathrm{MPa}$, and the maximum value is 16.43 MPa) is larger than those of the conventional structure and the new structure with protective covers, and no apparent peak value is shown in the distribution curve of the contact pressure, which illustrates that the shoulder protrusion of the packer rubber does not occur and the sealing properties are much better.

Then, the new packer rubber made of AFLAS with expanding back-up rings was installed on a packer, which was also put into the casing. The test scheme and the test procedure of the new packer rubber were the same as that of the packer rubber with protective covers in Plan 1. During 
Fig. 10 Schematic diagram of the performance test

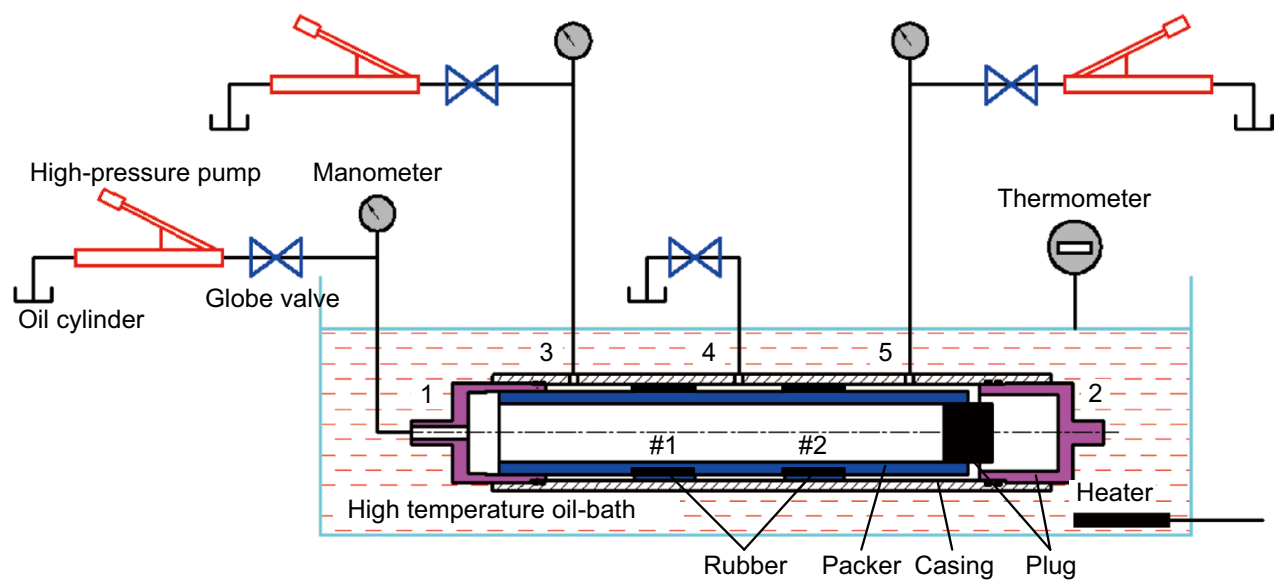

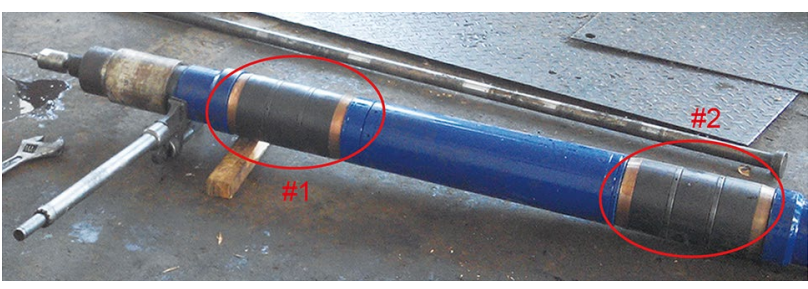

Fig. 11 Rubber barrels installed on a packer

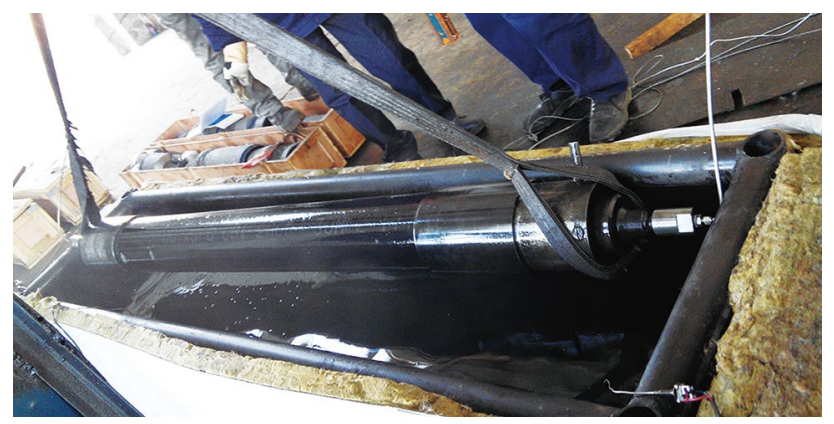

Fig. 12 Experimental equipment

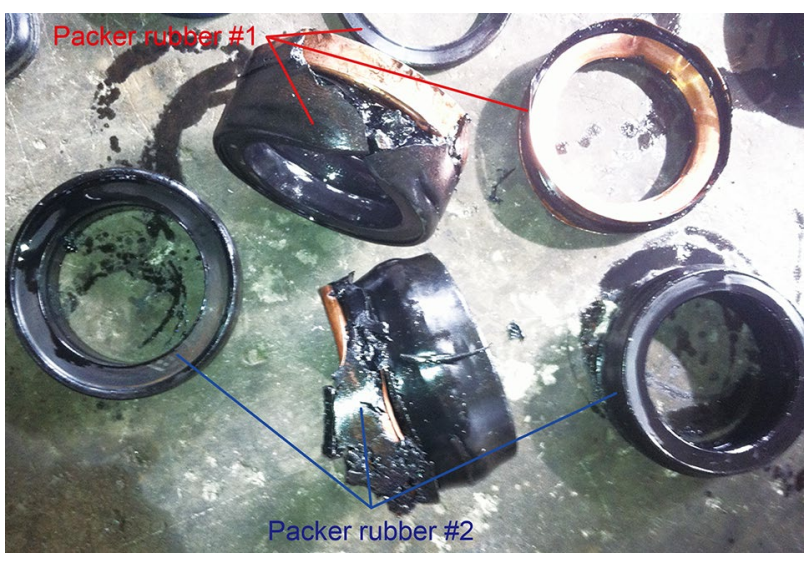

Fig. 13 Ruptured packer rubber made of HNBR the test, the sealing pressures in Hole 3 and Hole 5 of the test unit were increased gradually by the high-pressure pump and $10 \mathrm{MPa}$ was pressurized each time. The curve of the sealing pressures is shown in Fig. 19. The pressure was stable for $15 \mathrm{~min}$ in each stage. Finally, the maximum sealing pressures of the two holes reached 70-72 MPa which were stabilized for 25-30 min. After the test, the packer rubber was removed and the rubber barrel was still intact, as shown in Fig. 20. In contrast, the new packer rubber made of HNBR with expanding back-up rings was also installed on a packer and tested. However, the maximum sealing pressure only reached $56 \mathrm{MPa}$. The rubber barrels were removed, as shown in Fig. 21. The rubber barrels made of HNBR were ruptured which caused a variation of the sealing performance.

The results of both tests show that the new structure of the packer rubber (single rubber barrel with expanding backup rings) is reasonable and can work well under high temperature $\left(170^{\circ} \mathrm{C}\right)$ and high pressure $(70 \mathrm{MPa})$ after setting. AFLAS rubber has greater resistance to high pressure and high temperature than HNBR.

\section{Conclusions}

Based on ABAQUS software simulation and experimental studies of the packer setting, we performed the material selection and the structure optimization of the packer rubber for working well under high temperature and high pressure, and the following conclusions can be drawn:

(1) Two structure optimization schemes of the packer rubber are proposed. In each structure, both materials HNBR and AFLAS are tested. The results show that AFLAS rubber has greater resistance to high pressure $(70 \mathrm{MPa})$ and high temperature $\left(170^{\circ} \mathrm{C}\right)$ than HNBR. In the structure of three rubber barrels with metallic protective covers, both HNBR and AFLAS are subjected to varying degrees of damage which cause poor 


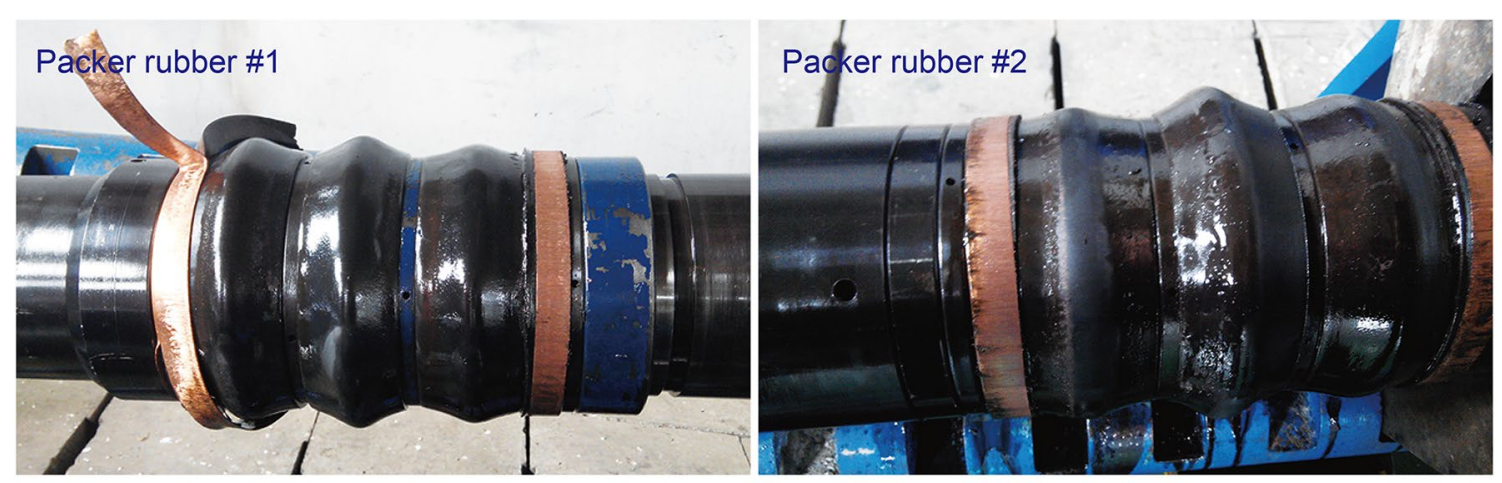

Test 1

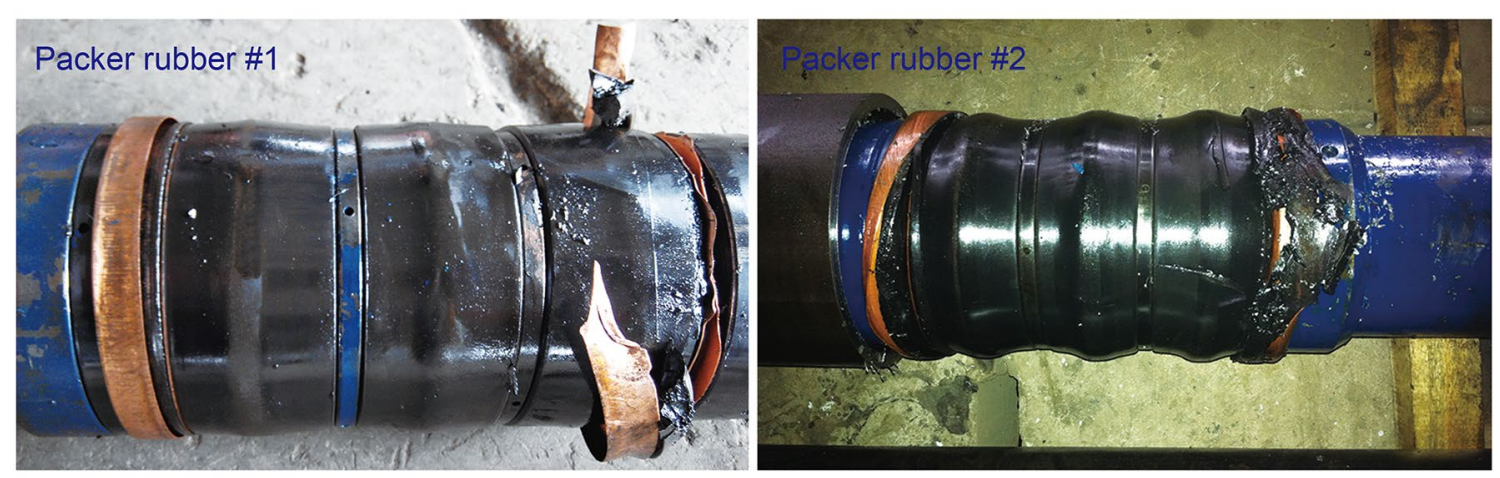

Test 2

Fig. 14 Packer rubber made of AFLAS after tests

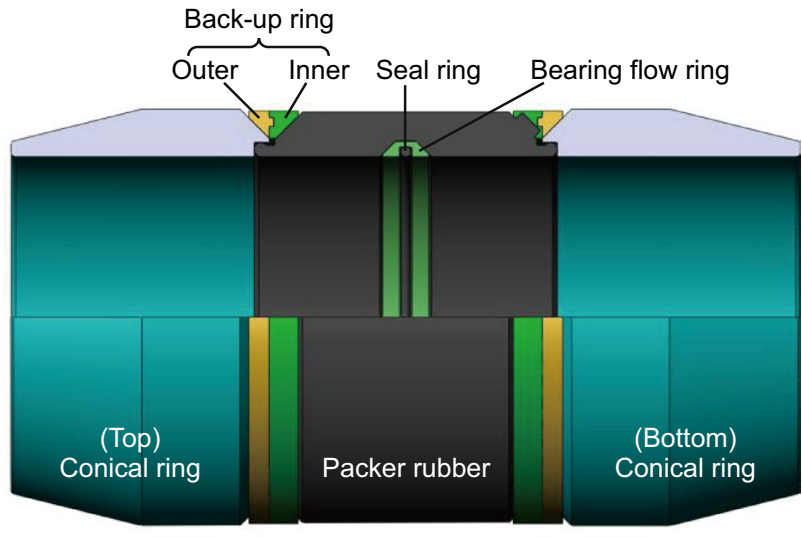

Fig. 15 Structure of a single rubber barrel with expanding back-up rings

sealing performances under high pressure and high temperature although the performance of AFLAS is better than that of HNBR. In the structure of a single rubber barrel with expanding back-up rings, the packer rubber made of HNBR is also ruptured but the packer rubber made of AFLAS works well under high temperature and high pressure after setting.

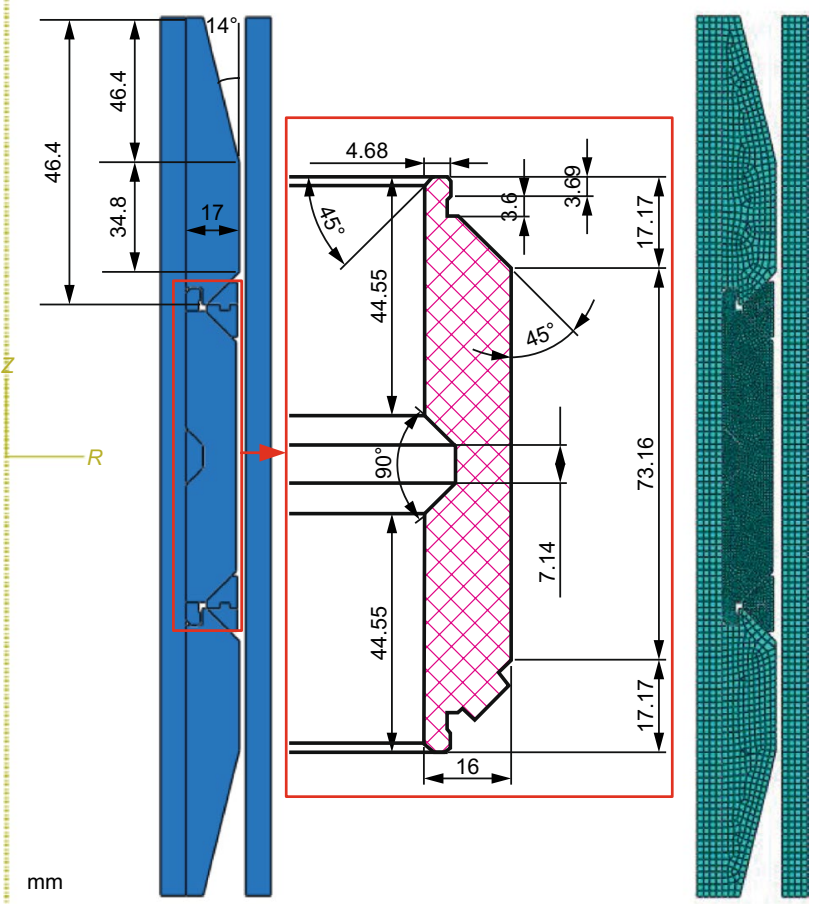

Fig. 16 Finite element model of the rubber barrel with expanding back-up rings 


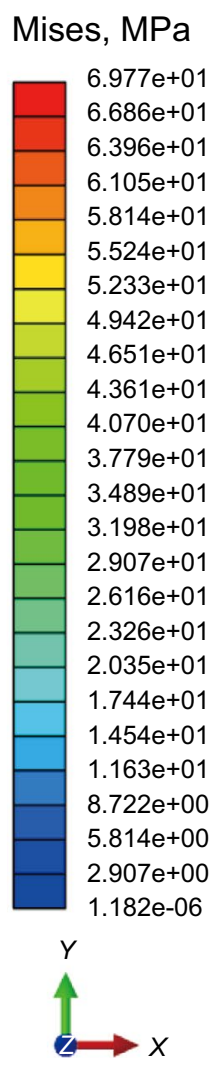

Magnitude, $\mathrm{mm}$
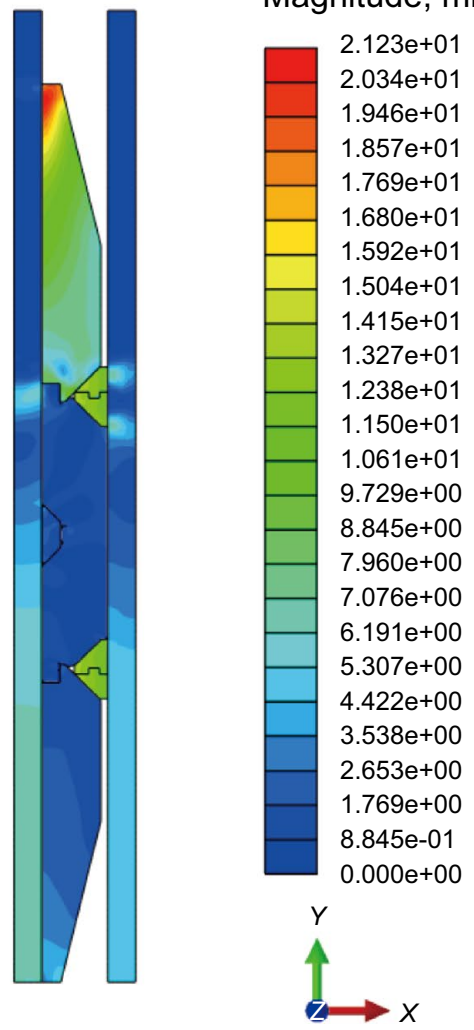

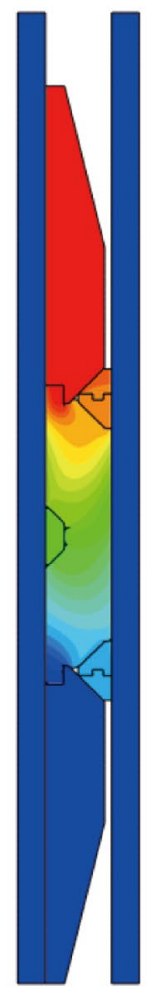

Contact pressure, $\mathrm{MPa}$

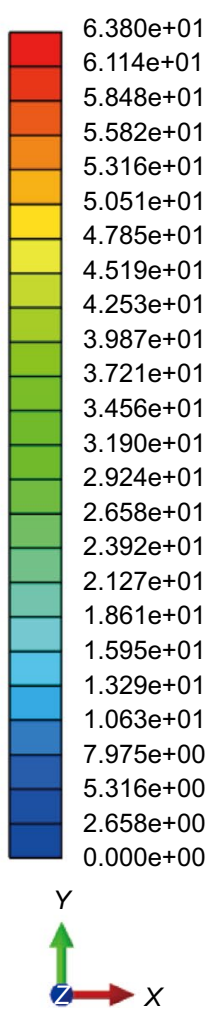

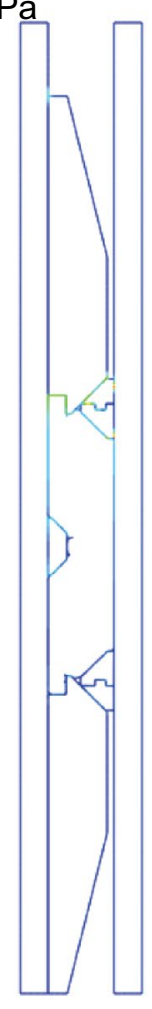

Fig. 17 Equivalent stress, strain and contact pressure distributions
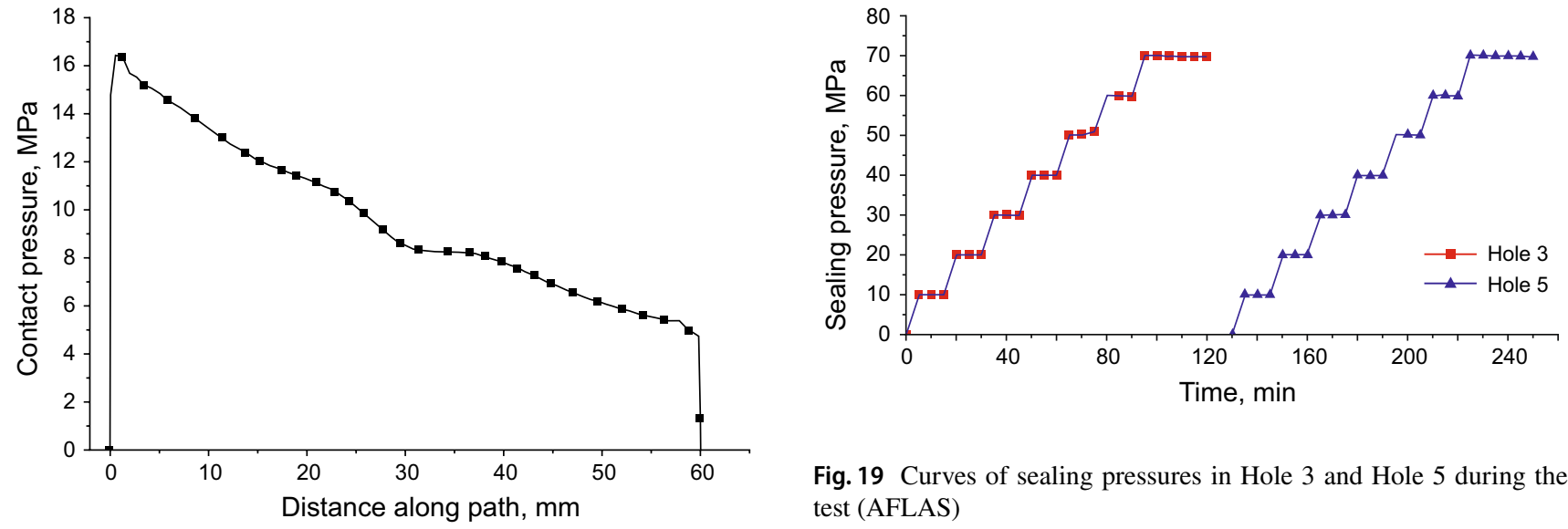

Fig. 19 Curves of sealing pressures in Hole 3 and Hole 5 during the test (AFLAS)

Fig. 18 Distribution of contact pressure between the casing and the packer rubber

(2) The structure of the single rubber barrel with expanding back-up rings and the material AFLAS are a good combination for the packer rubber providing an excellent sealing performance during the multistage fracturing of low-permeability reservoirs in offshore fields. In the new packer rubber, the middle single rubber barrel plays a major sealing role and there are two metal coni-

cal rings at both ends of the rubber barrel instead of the top and bottom rubber barrels in the construction of three rubber barrels to bear the thrust for setting. A dovetail groove is cut in the inner wall of the rubber barrel. There are a bearing flow ring made of metal and a seal ring (O-ring) in the groove to seal the space between the rubber barrel and the center pipe. 


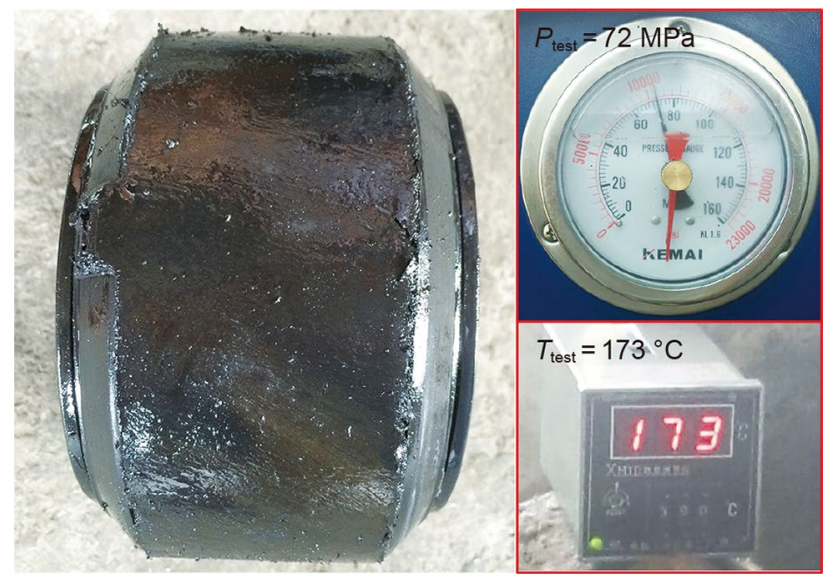

Fig. 20 New packer rubber made of AFLAS with expanding back-up rings after the test

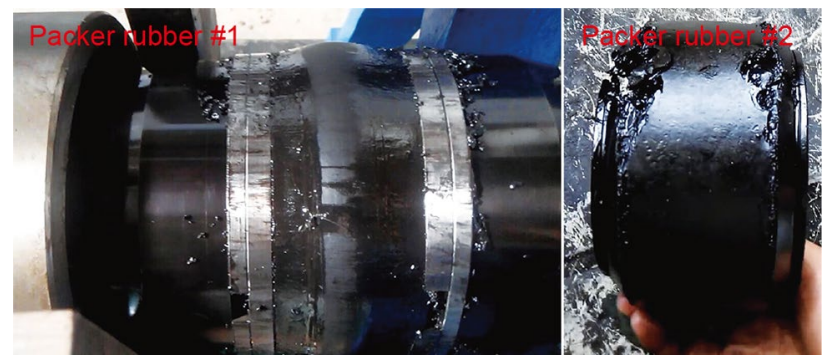

Fig. 21 New packer rubber made of HNBR with expanding back-up rings after the test

(3) A performance test scheme of the packer is designed which can simulate the packer setting and its working conditions well.

Acknowledgements We would like to thank the financial support from the Fundamental Research Funds for the Central Universities under Grant nos. 17CX05020 and 17CX06002, the Research Funds for Introducing Talent $(\mathrm{PhD})$ of China University of Petroleum under Grant no. YJ20170026, the National Science and Technology Major Project under Grant no. 2016ZX05042004 and the Joint Funds of the National Natural Science Foundation of China under Grant no. U1762104.

Open Access This article is distributed under the terms of the Creative Commons Attribution 4.0 International License (http://creativeco mmons.org/licenses/by/4.0/), which permits unrestricted use, distribution, and reproduction in any medium, provided you give appropriate credit to the original author(s) and the source, provide a link to the Creative Commons license, and indicate if changes were made.

\section{References}

Alcock B, Jørgensen JK. The mechanical properties of a model hydrogenated nitrile butadiene rubber (HNBR) following simulated sweet oil exposure at elevated temperature and pressure.
Polym Test. 2015;46:50-8. https://doi.org/10.1016/j.polymertes ting.2015.06.010.

Atkinson C, Desroches J, Eftaxiopoulos DA, Thiercelin M. Wellbore stresses induced by the nonlinear deformation of an inflatable packer. J Eng Math. 2001;41:305-27. https://doi.org/10.1023/A:10122 97324968.

Choudhury A, Bhowmick AK, Ong C. Effect of different nanoparticles on thermal, mechanical and dynamic mechanical properties of hydrogenated nitrile butadiene rubber nanocomposites. J Appl Polym Sci. 2010a;116:1428-41. https://doi.org/10.1002/app.30985.

Choudhury A, Bhowmick AK, Ong C. Influence of molecular parameters on thermal, mechanical, and dynamic mechanical properties of hydrogenated nitrile rubber and its nanocomposites. Polym Eng Sci. 2010b;50:1389-99. https://doi.org/10.1002/pen.21680.

Economides MJ, Nolte KG. Reservoir stimulation. Old Tappan: Prentice Hall Inc; 2000.

Gent AN. Engineering with rubber-How to design rubber components. 3rd ed. Munich: Carl Hanser Verlag GmbH Co KG; 2012.

Guo Z, Li Q, Wang Y, Sun B, Zhang S. Analysis and structural improvement of the rubber part in packer in a way of non-linearity finite element. In: IEEE second international conference on mechanic automation and control engineering, Hohhot, China, August, 2011. pp. 73-6. https://doi.org/10.1109/MACE.2011.5986860.

He X, Shi X, Hoch M, Gögelein C. Mechanical properties of carbon black filled hydrogenated acrylonitrile butadiene rubber for packer compounds. Polym Test. 2016;53:257-66. https://doi.org/10.1016/j. polymertesting.2016.06.009.

James D, Deng G, Scott C, Gary A, Shyu G. Permanent production packer pushes limits of ultra-HPHT wells. Drill Contract. 2013;69:166-72.

Liu P, Liu H, Xiao X, Liu X, Tang M, Ma B, et al. Improved tight oil productivity through integrated technology deployment on a multipad horizontal-well trial in central China. In: SPE/IADC Middle East drilling technology conference and exhibition, Abu Dhabi, 26-28 January, 2016. https://doi.org/10.2118/178143-MS.

Love TG, McCarty RA, Surjaatmadja JB, Chambers RW, Grundmann SR. Selectively placing many fractures in openhole horizontal wells improves production. SPE Prod Fac. 2001;16:219-24. https://doi. org/10.2118/74331-PA.

Ma W, Qu B, Feng G. Effect of the friction coefficient for contact pressure of packer rubber. Arch PI Mech Eng C-J Mec. 2014;228:2881-7. https://doi.org/10.1177/0954406214525596.

Polonsky VL, Tyurin AP. Design of packers for sealing of the inter-tube space in equipment used for recovery of oil and gas. Chem Petrol Eng. 2015;51:37-40. https://doi.org/10.1007/s10556-015-9994-2.

$\mathrm{Qu} \mathrm{B.} \mathrm{Effects} \mathrm{of} \mathrm{the} \mathrm{friction} \mathrm{coefficient} \mathrm{on} \mathrm{sealing} \mathrm{performance} \mathrm{of} \mathrm{packer}$ element. In: International conference on education, management, computer and society (EMCS), Shenyang, China, January, 2016. pp. 868-72. https://doi.org/10.2991/emcs-16.2016.213.

Wang J, Feng L, Mohr S, Tang X, Tverberg G, Höök M. China's unconventional oil: a review of its resources and outlook for long-term production. Energy. 2015;82:31-42. https://doi.org/10.1016/j.energ y.2014.12.042.

Wang Z, Lv F, Cao M, Wen H, Xu Y. Research on experimental method for the working force between packer rubber and casing tube. Appl Mech Mater. 2014;518:138-43. https://doi.org/10.4028/www.scien tific.net/AMM.518.138.

Ye Q, Lin H, Zhang C, Li F, Cheng S. Research and application for horizontal fracturing technology in the development of low-permeability oilfields. Drill Prod Technol. 2008;31:57-9 (in Chinese).

Zeng D, Yang X, Zhu D, Zhang Z, Cao D, Chong X, et al. Corrosion property testing of AFLAS rubber under the simulation modes of high acid gas wells. Energy Proc. 2012;16:822-7. https://doi. org/10.1016/j.egypro.2012.01.132.

Zeng Y, Zuo C, Bian X. Breakthrough in staged fracturing technology for deep shale gas reservoirs in SE Sichuan Basin and 
its implications. Nat Gas Ind B. 2016;3:45-51. https://doi. org/10.1016/j.ngib.2016.02.005.

Zhang J, Li W, Zhang S. Experimental study of the mechanical properties of rubber for packer sleeves. Chin J Mech Eng. 2011;47:71-6. https ://doi.org/10.3901/JME.2011.08.071 (in Chinese).

Zhu D, Lin Y, Zhang H, Li H, Zeng D, Liu W, et al. Corrosion evaluation of packer rubber materials in $\mathrm{CO}_{2}$ injection wells under supercritical conditions. J Petrol Sci Eng. 2017;151:311-7. https:// doi.org/10.1016/j.petrol.2017.01.012.

Zhu X. Basis of packer design. Beijing: China Petrochemical Press; 2012 (in Chinese). 